\title{
Experimental Investigation of Energy Release Rate for In-plane Shear Mode in GFRP Composites
}

\author{
Manjunath.B.T ${ }^{1}$, Suneel Kumar N Kulkarni ${ }^{2}$, Kirthan. L.J ${ }^{3}$ \\ ${ }^{1,2}$ Department of Mechanical Engineering, BTL Institute of Technology \\ Hosur Road, Bangalore, Karnataka, India \\ ${ }^{1}$ manjunathbtlit@gmail.com, ${ }^{2}$ principal.btlit@gmail.com \\ ${ }^{3}$ Department of Mechanical Engineering, R V College of Engineering \\ Mysore Road, Bangalore, Karnataka, India \\ ${ }^{3}$ kirthanlj@rvce.edu.in
}

\begin{abstract}
The main drawback of fiber reinforced composites is inter-laminar fracture, especially delamination. Due to the nature of composite fabrication delamination is being a common failure. Composites are made in a variety of manufacturing techniques that are available. Commonly, a layered stacking of fibers in a primary plane is observed in each of these techniques. The interfacing part between the layers of the composites is not obviously reinforced with fibers which in turn lead to the inter-laminar fracture or delamination. The strain energy release rate $\left(G_{C}\right)$ is the best material property that can represent the resistance to delamination which can be both experimentally and numerically obtained. The principal attention of the present study is to obtain the inter-laminar fracture toughness in composites caused because of the pure sliding mode. An inter-laminar fracture for mode II ( $\mathrm{G}_{\text {IIC }}$ ) crack propagation is studied for GFRP materials having unidirectional 00 orientation of fiber. Compliance calibration method is used to study on the experimental investigation of toughness $G_{\text {IIC }}$ for fiber volume of $40 \%, 50 \%$ and $60 \%$. Investigation was directed according to ASTM D7905 using End Notched Flexure specimen which is fabricated using E-glass fiber and epoxy matrix in hand layup method. Results obtained are again correlated with numerical analysis using virtual crack closure technique (VCCT) method.
\end{abstract}

Keywords: Energy Release rate, Fracture Toughness, Virtual Crack Closure technique, Edge Notch Flexure specimen.

\section{INTRODUCTION}

The composite materials undergo failure due to many aspects like impact or static overloading, fatigue, overheating, hygrothermal effect, creep etc. One of the most regularly used manufacturing technique used of set up a composite structure is laminating of composite materials. Delamination is being the major limiting factor for the composite structures that are laminated. Delamination being a mainly significant mode of failure observed particularly in reinforced fiber laminate composites structures. Delamination is the separation of the laminated fiber reinforced layers that are bonded together to form laminated composite. These de-laminations are the results of the impact by any foreign object or manufacturing defects and this can cause a significant reduction in strength and stiffness of the component or the structure. Linear fracture mechanics depending on energy have been extensively used in de-lamination model of composite and their study. The strain energy release rate ' $G$ ' to be verified for resolving loads that cause delamination expansion by using this fracture mechanics approach. In some of the conditions that involve the inter-laminar fracture-toughness or critical strain-energy-release rate, ' $\mathrm{G}_{\mathrm{C}}$ ' in composites. The energy that is released for the crack to grow for unit area in the test specimen undergoing constant displacement is called as the strain-energy-release rate. The capacity of a material having a crack to resist the growth of fracture on that material is called as critical strain energy release rate or Inter laminar fracture-toughness. At critical load the critical value of energy release rate obtained. The End notch flexure (ENF) specimens to be tested are designed and performed the tests to measure inter laminar fracture toughness of delamination under mode II crack growth [3]. The fracture toughness of delamination of Mode II is measured under different environmental and loading conditions. The critical-strain-energy-releaserate for crack expansion in mode II is measured to be about $7553 \mathrm{~J} / \mathrm{m} 2$. The finite element analysis of interlaminar fracture-toughness measurement in mode II on the ENF specimen is conducted [5]. The effect of the friction between crack faces and the large deflection on top of the evaluation of sliding mode (mode II) fracturetoughness 'GIIC' from the ENF specimen is investigated. This analysis showed so as to the frictional cause is insignificant only at the time of the crack length is greater than one-fourth to length of that specimen. Also, to evaluate 'GIIC' when deflection is greater than that of the thickness of specimen, the geometric nonlinear analysis is required. 


\section{A. Objectives}

\section{OBJECTIVES AND METHODOLOGY}

The objectives of present study were to fabricate End Notched Flexure (ENF) specimen using a Glass Reinforced Polymer (GRP) composite for volume fractions 0.4, 0.5 and 0.6.An experimental investigation to obtain strain-energy-release-rates for inter-laminar composite structures undergoing mode II crack propagation using the standard End Notched Flexure specimen is performed.Analysis and prediction of the delamination growth in composite material (GRP) using Fracture Mechanics approach is executed.Extraction of Strain energy-release-rate GII values for $40 \%, 50 \%$ and $60 \%$ volume of fiber is done along with analyzing and optimizing the Inter-laminar Fracture Toughness GIIC for mode II loading in Glass/Epoxy material for the above mentioned volume fractions.

\section{B. Methodology}

The end notched flexure specimen of E-glass/epoxy is laminated by hand layup method for volume fractions 0.4, 0.5 and 0.6 according to ASTM D 7905.Conducting standardized tests (three point bending test) for characterizing fracture-toughness GFRP under sliding mode crack propagations. The second mode inter-laminar fracture behavior in the Reinforced Glass epoxy laminate material by uniformly increasing load on the specimen will be examined by End Notch Flexure (ENF) specimen. Inter-laminar Fracture Toughness for the End Notch flexure specimen is calculated by using the peak load at which the crack propagates in the Compliance Calibration Method [4] (CCM).Numerical study of crack propagation will be done by VCCT (Virtual Crack Closure Technique). ANSYS V14.0 will be used for numerical studies. Thorough comparison will be done between Numerical and Experimental methods. Optimizing the fracture toughness for different volume fractions mentioned above. Validating the results obtained from experimental and numerical methods. Compare the numerical results obtained with the other modes of fracture for the same peak loads.

\section{FABRICATION}

In the fabrication process of GRP composites, the materials that are used are as follows -

a. Epoxy Resin- Reinforcement material.

b. E-Glass Fiber- Matrix material

c. Hardener- HV $953 \mathrm{U}$

d. Releasing agent

TABLE 1 Properties of Fiber and Matrix

\begin{tabular}{|c|c|c|c|c|}
\hline Material & $\begin{array}{c}\text { Density } \rho \\
\left(\mathrm{Kg} / \mathrm{m}^{3}\right)\end{array}$ & $\begin{array}{c}\text { Elastic modulus } \\
(\mathrm{GPa})\end{array}$ & $\begin{array}{c}\text { Shear modulus } \\
(\mathrm{GPa})\end{array}$ & $\begin{array}{c}\text { Poisson's } \\
\text { ratio }\end{array}$ \\
\hline Epoxy & 1200 & 4.5 & 0.034 & 0.4 \\
\hline E glass & 2600 & 74 & 0.032 & 0.25 \\
\hline
\end{tabular}

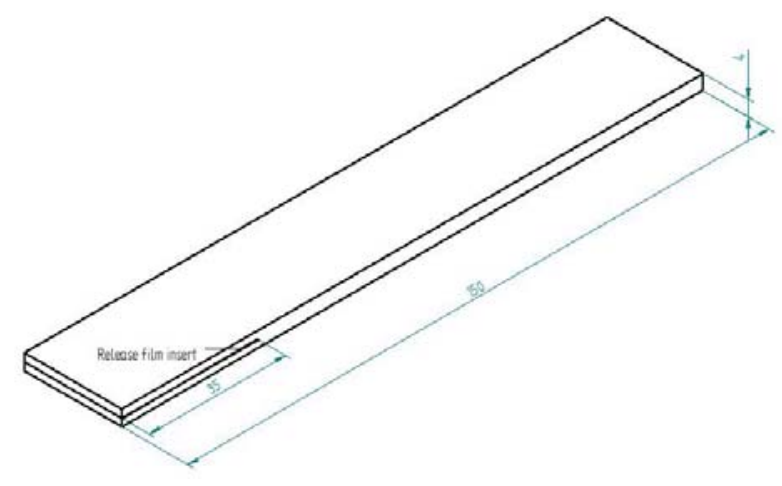

Fig 1. ENF Specimen model 


\section{A. Elastic Constants of the Unidirectional E-glass/ Epoxy Composite}

The orthotropic elastic constants are calculated from the E glass and Epoxy material property, depending on the percentage of volume present in the composite. An equation from rules of mixture was adopted for extracting the 9 elastic constants.

TABLE 2 Elastic constants of E-glass/Epoxy laminate

\begin{tabular}{|c|c|c|c|c|}
\hline Fiber volume & $\mathrm{E}_{11}(\mathrm{GPa})$ & $\mathrm{E}_{22}=\mathrm{E}_{33}(\mathrm{GPa})$ & $v_{12}=v_{13}$ & $\mathrm{G}_{12}=\mathrm{G}_{13}(\mathrm{MPa})$ \\
\hline 0.4 & 32.3 & 7.207 & 0.34 & 32.771 \\
\hline 0.5 & 39.25 & 8.484 & 0.325 & 32.969 \\
\hline 0.6 & 46.2 & 10.31 & 0.31 & 33.17 \\
\hline
\end{tabular}

B. Dimensions of the End Notch Flexure Specimen as Per ASTM D7905

The dimensions of the Edge Notch Flexure specimen are as per the ASTM D7905 Standard and the loading and boundary conditions are shown as shown in Figure 2.

\section{ALL DIMENSIONS IN MM}

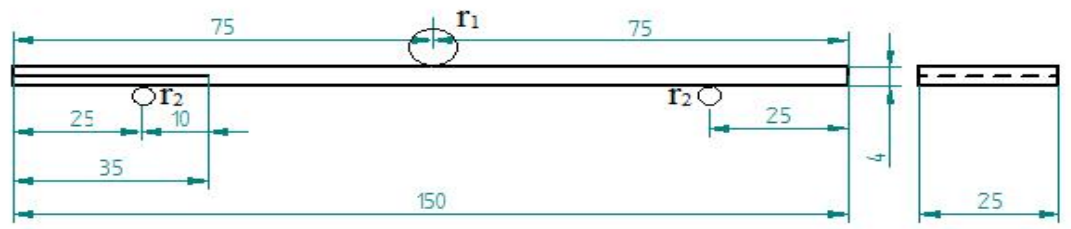

Fig 2. Dimensions of ENF specimen

The prepared specimen is approximately cured in the room temperature for $24 \mathrm{hrs}$. Once the specimen is dried, the specimen is taken out of the mould and cleaned. The extra fiber is cut and the edges are trimmed. After trimming the edges, the specimen is ready to use. The finished ENF specimens along with the release film inset after edges of the specimen is trimmed different volume fractions are shown in the fig. 3 . The release film acts as the pre-crack in the specimen.

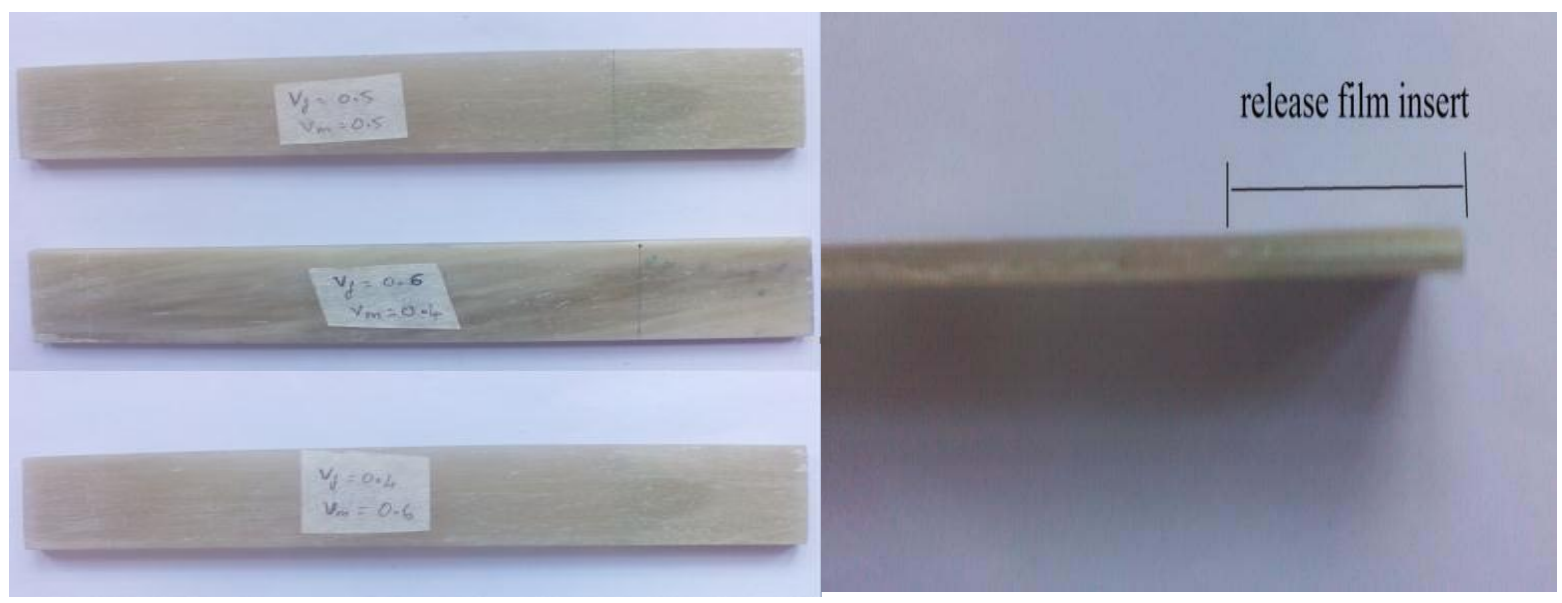

Fig.3 ENF specimen after fabrication Release film insert in the specimen 


\section{EXPERIMENTAL INVESTIGATION}

The ENF samples shown in Fig. 3 contain a unidirectional, laminated composite having cross section of rectangle and even thickness sample. They also are containing a non-adhesive film at middle of the plane which acts as the initiator of the crack. Loads are acted on the sample through an ENF fixture under displacement controlled loading.

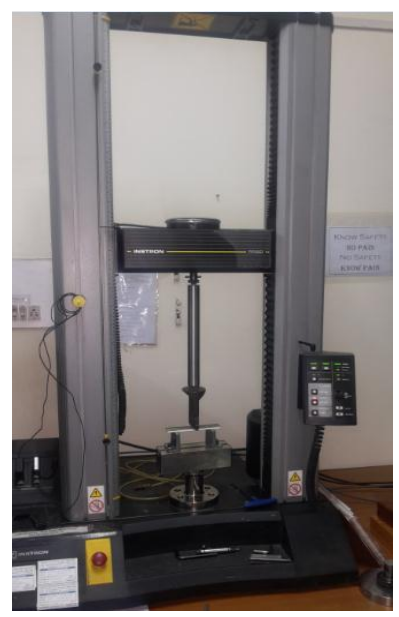

Fig.4 INSTRAN Universal Testing Machine

Universal Testing Machine was used to carry out the experiment to obtain the peak load at which the crack propagates. Digital load against deflection recorder connected INSTRON Universal Testing Machine of maximum capacity $10 \mathrm{KN}$ is used to perform three point bending test.

$$
\begin{aligned}
G & =-\frac{1}{B} \frac{d U}{d a} \\
G_{Q} & =\frac{3 m P_{\text {max }}^{2} a_{0}^{2}}{2 B}
\end{aligned}
$$

For any specimen where the candidate toughness is accepted having the condition as

$$
\boldsymbol{G}_{\text {IIC }}=\boldsymbol{G}_{\mathbf{Q}}
$$

A values of the force applied against displacement of the center roller are recorded. A real-time plotting device or an equivalent $x-y$ recorder is used to obtain the plot and digitally store the values[6]. Compliance Calibration (CCM) Method is used to calculate inter-laminar fracture toughness, $\mathrm{G}_{\mathrm{IIC}}$.

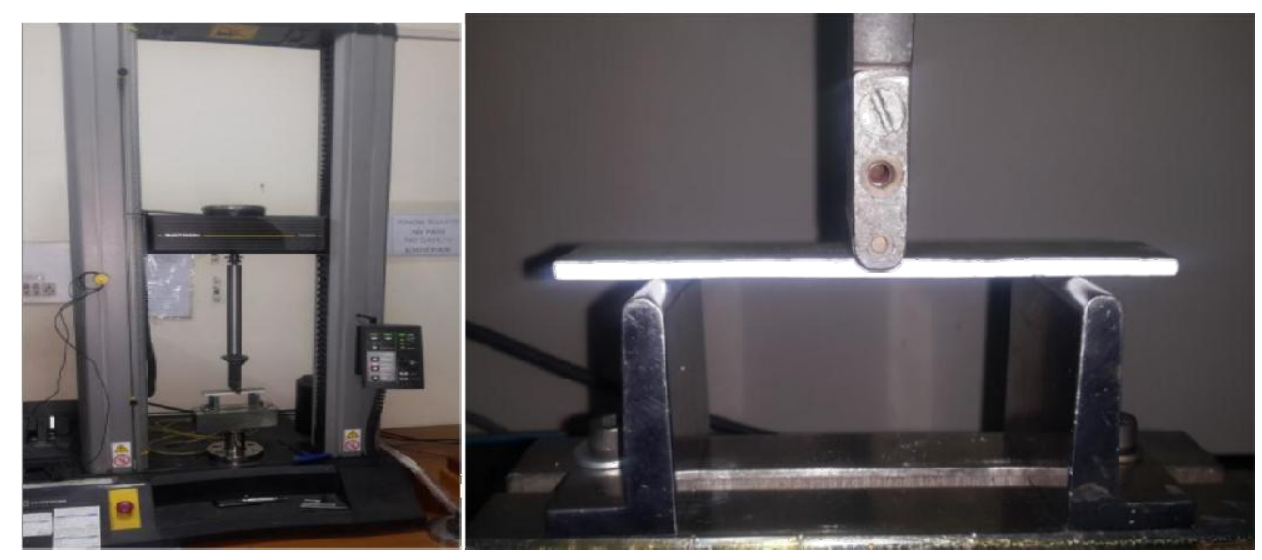

Fig.5 Specimen placed in the fixture 


\section{NUMERICAL INVESTIGATION}

From the literature survey Virtual Crack Closure Technique being the best analytical method that can find strain energy release rate. Virtual crack closure technique is getting popular, especially in aerospace engineering fields, as this technique have effective suitability of the technique for modeling behavior and the practical computation time for an anisotropic material. The crack growth predicted in VCCT is by comparing local strain-energy-release-rate with the fracture toughness. Results obtained in a finite element model from node to node strain-energy-release-rate using VCCT, Simulation of delamination behaviors are done in VCCT very effectively for the composite structures. Simulation of the crack growing and after damage residual strength of a composite structure can be estimated using VCCT [9].

In virtual crack closure technique, development in crack length is modeled by having an interaction contact which is defined between two crack surfaces. Hence, the crack growth is predefined. Crack propagation prediction is obtained by comparing the critical strain energy release rate $(\mathrm{Gc})$ with strain-energy-release-rate (G) of required material. An assumption is made that the energy necessary to does not modify considerably at the time of crack extending from a to $\mathrm{a}+2 \mathrm{a}$ (node $\mathrm{k}$ ) from $\mathrm{a}+\mathrm{a}$ (node i). So after crack tip the displacement at node $i$ is roughly same as the displacement after the original crack tip at node 1 . Simple formulas to the calculation of strain-energy-release-rate using VCCT are given below for a 3D solid 8-noded element close crack is same as energy lost while the crack starts growing from ' $a$ ' to ' $a+\Delta$ ' $a$ '. In VCCT the state at the crack tip.

SOLID185 is used for meshing of a solid three dimensional structure. It is a eight nodded brick element having nodes on each of the edges. TARGE170 is the element used for creating the target surface on which the strain energy is to be obtained. TARGE170 can be used when the contact elements CONTA172, CANTA175 are used. CONTA174 is the element which is used to create the contact surface on the crack surface. It is a 3D 8 nodded element. One crack surface is the contact surface and other is target surface

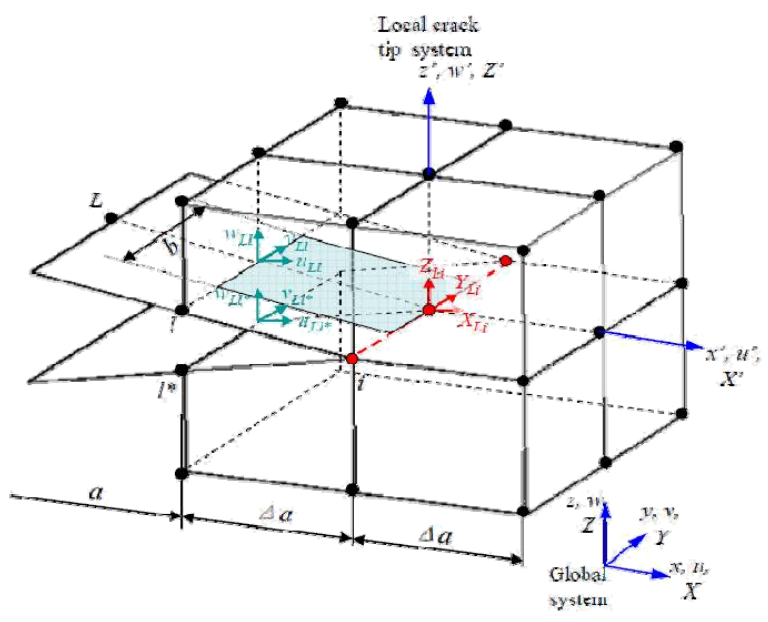

Fig.7 VCCT for a solid element

\section{RESULTS AND DISCUSSION}

The graph of load against displacement is obtained in the Universal Testing Machine digital recorder. Peak load or the maximum load by which the propagation of crack through the sample is found in the load versus deflection curve. This peak load or the critical load is used to find the Compliance, inter-laminar fracture toughness and the stress intensity factor using equations (5.3), (5.5) and (5.6) respectively. The results obtained are compared with each other to find the fiber volume fraction at which possesses high inter-laminar fracture toughness. As the glass fiber reinforced polymer is a brittle material the load V/S curve drop vertically after the peak load. 


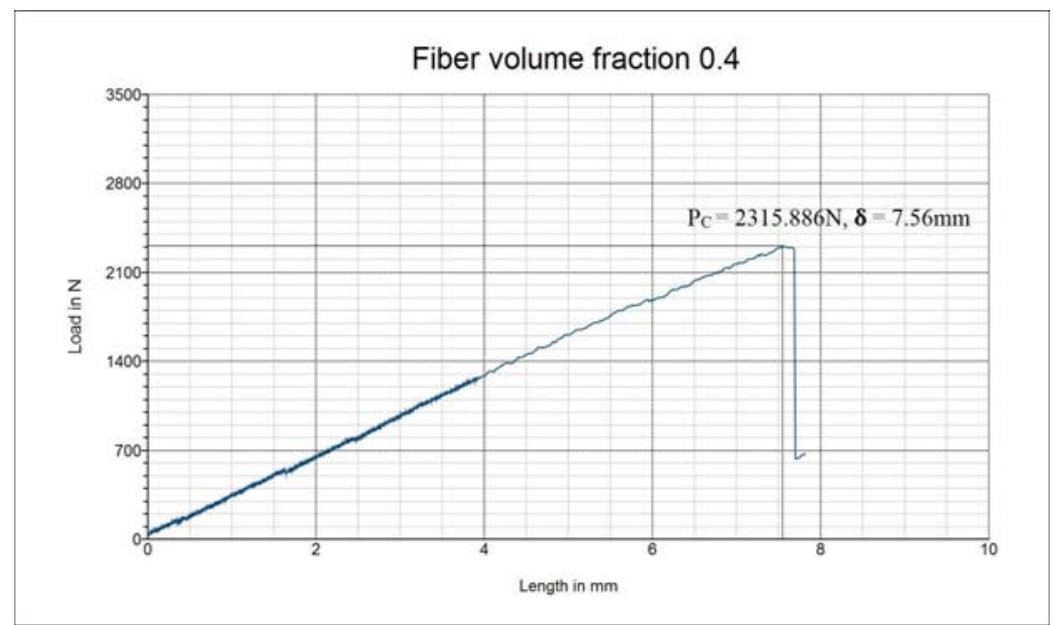

Fig.7 Load/displacement for fiber volume fraction $40 \%$

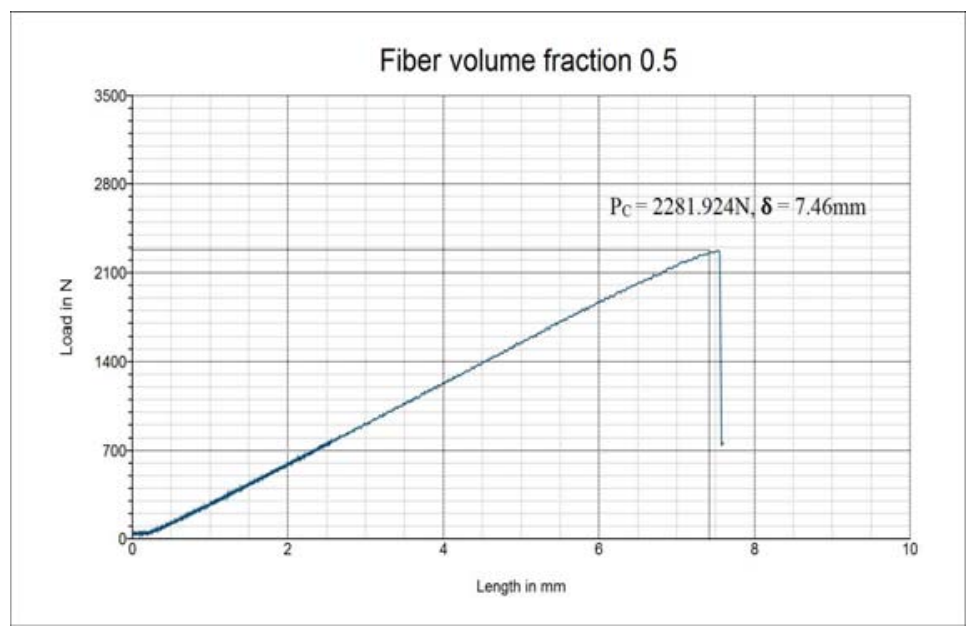

Fig.8 Load/displacement for fiber volume fraction $50 \%$

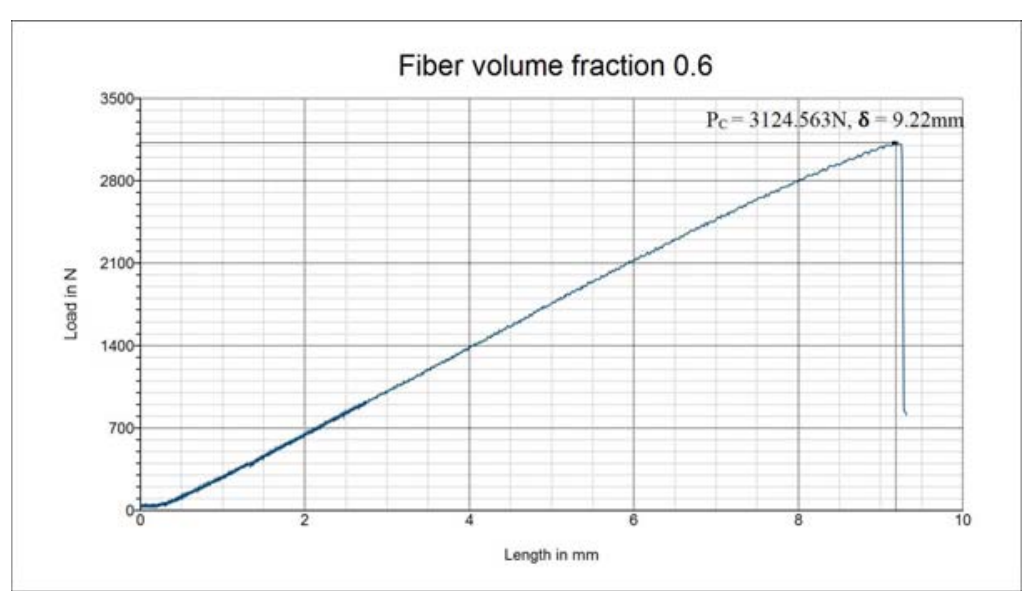

Fig.9 Load V/S displacement for fiber volume fraction $60 \%$

The maximum load for $40 \%$ volume fraction from the recorded is $2315.886 \mathrm{~N}$ at the deflection of $7.56 \mathrm{~mm}$ from figure 7. And the energy release rate was found to be $\mathrm{G}_{\mathrm{IIC}}=1.846 \mathrm{~J} / \mathrm{mm}^{2}$. 
TABLE 3 Experimental results for each of the fiber volume fraction

\begin{tabular}{|c|c|c|}
\hline Fiber volume & $\begin{array}{c}\text { VCCT G } \\
\mathrm{J} / \mathrm{mm}^{2}\end{array}$ & $\begin{array}{r}\text { Experimental } \mathrm{G}_{\mathrm{IIC}} \\
\mathrm{J} / \mathrm{mm}^{2}\end{array}$ \\
\hline $40 \%$ & 0.62705 & 1.846 \\
$50 \%$ & 0.48649 & 1.476 \\
$60 \%$ & 0.75222 & 2.347 \\
\hline
\end{tabular}

The maximum load for $50 \%$ volume fraction from the recorded is $2281.924 \mathrm{~N}$ at the deflection of $7.46 \mathrm{~mm}$ from figure 8 . And the energy release rate was found to be $\mathrm{G}_{\mathrm{IIC}}=1.476 \mathrm{~J} / \mathrm{mm}^{2}$. The maximum load for $60 \%$ volume fraction from the recorded $3124.563 \mathrm{~N}$ at the deflection of $9.22 \mathrm{~mm}$ from figure 9 . And the energy release rate was found to be $\mathrm{G}_{\mathrm{IIC}}=2.347 \mathrm{~J} / \mathrm{mm}^{2}$.

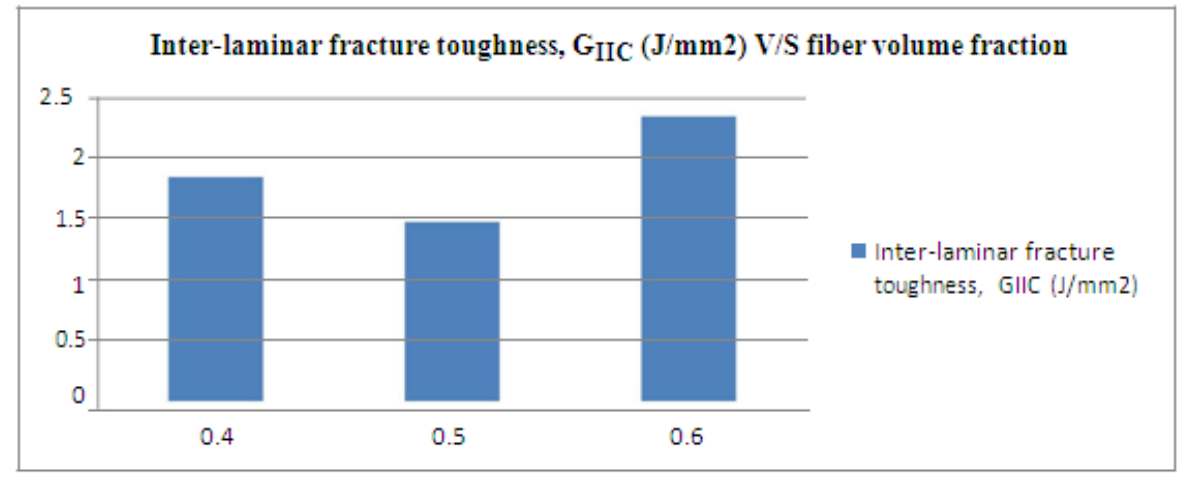

Fig. 10 Comparison of $\mathrm{G}_{\text {IIC }}$ with volume fractions

VCCT technique is used for the numerical analysis in ANSYS software. The strain-energy-release-rate can be obtained at each crack tip node directly in VCCT. The best numerical method that can be used for analysis of fracture is VCCT as for the literature survey.

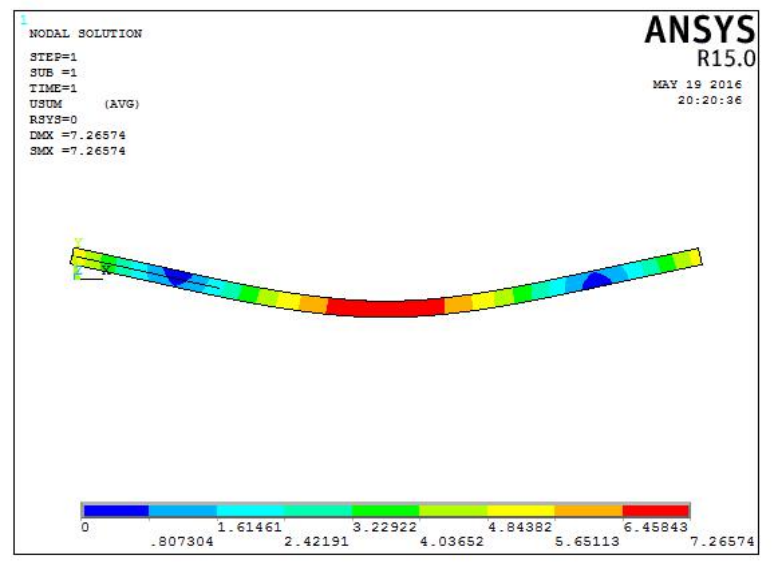

Fig. 11 Deformed shape of ENF with the crack

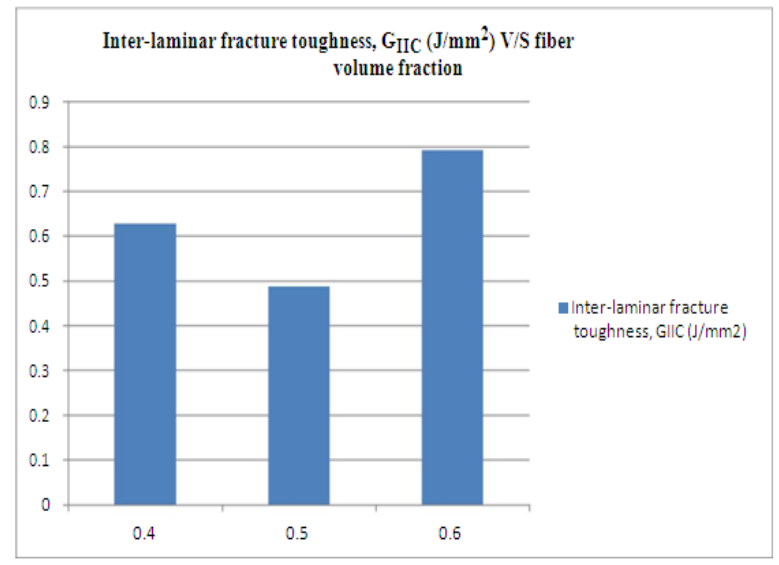

Fig.12 VCCT strain energy release rate V/S fiber volume

Figures 11 and 12 show the crack simulation and the comparison of energy release rate with the fiber volume. 
TABLE 4 Comparison of Experimental and Numerical results for fracture toughness

\begin{tabular}{|c|c|c|}
\hline $\begin{array}{c}\text { Fiber volume } \\
\text { fraction, } \mathrm{V}_{\mathrm{f}}\end{array}$ & $\begin{array}{c}\text { Compliance, } \mathrm{C} \\
(\mathrm{mm} / \mathrm{N})\end{array}$ & $\begin{array}{c}\text { Inter-laminar fracture } \\
\text { toughness, } \mathrm{G}_{\mathrm{IIC}}\left(\mathrm{J} / \mathrm{mm}^{2}\right)\end{array}$ \\
\hline 0.4 & $4.84 \times 10^{-3}$ & 1.846 \\
\hline 0.5 & $3.986 \times 10^{-3}$ & 1.476 \\
\hline 0.6 & $3.38 \times 10^{-3}$ & 2.347 \\
\hline
\end{tabular}

\section{VII.CONCLUSION}

Mode II crack propagation is analyzed and variation of Energy-Release-rate with change in volume of fiber is studied for a Glass fiber reinforced polymer composite using the End Notched Specimen through experimental method and also numerical techniques is carried out for the same fiber volume fractions.

This study was carried out for a unidirectional 00 orientation of E-glass fiber reinforced with the Epoxy, orthotropic properties of the composite was considered in numerical method. The specimen is prepared using the hand lay-up method for the experimental method for fiber volumes $40 \%, 50 \%$ and $60 \%$. The results obtained clearly display that the specimen having $60 \%$ fiber volume has high inter-laminar fracture toughness in both in experimental and numerical methods in mode II or the sliding mode. It is observed that the inter-laminar fracture toughness in the lower composition of the fiber in GFRP does not change significantly. Therefore, for resistance of crack propagation the higher composition of glass fiber volume in the GFRP composite laminate is desired.

It is found that composite having fiber volume fraction 0.6 is desired to resist the growth of crack. The outcomes of the present investigation till now are fairly acceptable.The analytical outcomes which are compared with the experimental outcomes and much difference in the compared outcomes were not found and at greater percentage of volume of fiber in reinforced glass fiber polymer composite, it is noticeably observed from both experimental and numerical techniques that the resistance to propagate crack in Mode II is greater.

\section{REFERENCES}

[1] Amit Kumar Tanwer, "Mechanical Properties Testing of Unidirectional and Bi-directional Glass Fiber Reinforced Epoxy Based Composites", International Journal of Research in Advent Technology, Vol.2, No.11, November 2014 E-ISSN: $2321-9637$

[2] Sandeep M.B, D.Choudhary, Md. Nizamuddin Inamdar, Md. Qalequr Rahaman,

[3] "Experimental study of effect of Fiber Orientation on the Flexural strength of glass/epoxy composite material", IJRET: International Journal of Research in Engineering and Technology eISSN: 2319-1163, pISSN: 2321-7308, Volume: 03 Issue: 09, Sep-2014

[4] Gwo-Chung Tsai, "Design of Composite ENF Specimens and Conduct Three-Point Test to Calculate Mode II Fracture Toughness", , 9th International Conference on Engineering Education, July 23-28 2006, no. R4D-18 to 22

[5] Russell A.J "On the measurement of mode II interlaminar fracture energies", , Defence Research, Establishment Pacific, Victoria, Material report 82, December, 1982.

[6] S. Mall and N. K. Kochhar, "Finite element analysis of end notch flexure specimen", University of Missouri-Rolla, missouri, Grant nagl-425, May 1986

[7] Carlsson L A, Gillespie J W and Trethewey B J, "Mode II interlaminar fracture toughness in graphite/epoxy and graphite/PEEK composites", Reinf. Plast Compos, 5(1986) pp.170-87.

[8] Sailendra N. Chatterjee, "Analysis of Test Specimens for Interlaminar Mode II Fracture Toughness, Part 1. Elastic Laminates", Journal of Composite Materials May 1, 1991 25: 470-493.

[9] R.Marat Mendes, M. Freitas, "DCB, ENF AND ECT Tests for Interlaminar Fracture of glass/epoxy Unidirectional laminates", $10^{\text {th }}$ Portuguese Conference on Fracture - 2006.

[10] Ronald Krueger, "Virtual crack closure technique: History, approach, and applications", American Society of Mechanical Engineers, Appl Mech Rev, vol 57, no 2, March 2004.

[11] S.Pichi Reddy, P.V.Chandra Sekhar Rao, A.Chennakesava Reddy, G.Parmeswari, “Tensile and Flexural Strength of Glass Fiber Epoxy Composites", International Conference on Advanced Materials and manufacturing Technologies (AMMT) December 18-20, 2014

[12] M.F.S.F. de Moura, R.D.S.G. Campilho , J.P.M. Gonçalves "Pure mode II fracture characterization of composite bonded joints", International Journal of Solids and Structures 46 (2009) 1589-1595 